\title{
LÍNGUA PORTUGUESA E IRRIGAÇÃO E DRENAGEM: A INTERDISCIPLINARIDADE COMO ELO
}

\author{
Antonio Hélder Rodrigues Sampaio* \\ Clélia Gomes dos Santos** \\ Nêmia Ribeiro Alves**
}

RESUMO: Este trabalho apresenta uma reflexão sobre a prática interdisciplinar no âmbito do Instituto Federal de Educação, Ciência e Tecnologia Baiano - IF Baiano, campus de Bom Jesus da Lapa, entre as disciplinas Irrigação e Drenagem e Língua Portuguesa. A prática foi realizada com turmas do terceiro ano do Curso Técnico Integrado ao Ensino Médio em Agricultura, utilizando como ponto de partida a leitura literária das obras O quinze de Raquel de Queiroz e Vidas secas de Graciliano Ramos. Para tanto, alguns temas convergentes às duas disciplinas foram discutidos como: interpretação textual, figuras de linguagens, ortografia, recursos hídricos do semiárido brasileiro características de solo e vegetação do bioma caatinga, uso da água de forma eficiente para realizar a irrigação e promover a produção de alimentos. Foi possível perceber, que o diálogo entre disciplinas do eixo tecnológico e comum é possível, o que trouxe uma maior participação e interesse dos alunos, já que os conteúdos foram discutidos a partir da realidade local, considerando o perfil dos ingressantes no curso. Para tal, estudos de Fazenda (2011), Japiassu (1979) e Veiga (2008) foram tomados como base teórica.

PALAVRAS-CHAVE: Interdisciplinaridade; Leitura literária; Língua portuguesa; Irrigação e drenagem.

\section{Introdução}

Diversas são as discussões acerca da organização do conhecimento escolar em disciplinas, modelo pensado pela Ciência Moderna que vê a divisão e classificação como soberana no processo de ensino e aprendizagem. Porém há a percepção de que esse mesmo método que fragmenta o conhecimento não é capaz de aglutiná-lo novamente, o que impossibilita a compreensão do todo e dificulta a produção de conhecimento, uma vez que a

\footnotetext{
* Doutor em Ciências Agrárias pela Universidade Federal do Recôncavo da Bahia (UFRB). Professor do Instituto Federal Baiano (IFBaiano), Campus Bom Jesus da Lapa.

** Mestre em Letras: Cultura, Educação e Linguagens, pela Universidade Estadual do Sudoeste da Bahia (Uesb). Professora EBTT no Instituto Federal Baiano (IFBaiano), Campus Bom Jesus da Lapa.

${ }^{* * *}$ Doutoranda em Literatura pela Universidade de Brasília (UnB). Mestre em Letras pela Universidade Estadual de Montes Claros. Professora do Instituto Federal de Educação, Ciência e Tecnologia do Norte de Minas Gerais (IFNMG).
} 
aprendizagem deve propor ao aluno a compreensão do mundo de modo que ele possa interagir com outras formas de conhecimento.

A disciplinaridade interfere tanto não compreensão da totalidade, tanto por parte de aluno quanto de professores, pois na maioria das vezes as partes são estudadas independentes uma das outras. Para Santomé (1998: 25), “em geral, poucos estudantes são capazes de vislumbrar algo que permita unir ou integrar os conteúdos ou o trabalho das diferentes disciplinas". Assim, os conteúdos parecem aos alunos algo sem sentido e distante da realidade cotidiana, o que dificulta o prazer em aprender e a vontade de participar efetivamente do processo educacional.

Ao se discutir questões do ambiente escolar, as quais envolvem o processo de ensino, é necessário refletir as dinâmicas pedagógicas desenvolvidas pelos professores como ferramentas fundamentais para com todo o processo, inclusive demandas que apontam para um novo paradigma da educação que defende um ensino-aprendizagem no qual, os professores precisam adotar a postura de mediadores, privilegiando os aspectos globais em função do comportamento particularizados. Nessa configuração pedagógica, consolidamse ações voltadas para a preparação de um aluno capaz de conviver em uma sociedade em constantes mudanças, tornando-se construtores de seu conhecimento, sujeitos ativos do processo educativo no qual a sensibilidade e razão são componentes.

Segundo Veiga (1996, p. 79), o professor deve ser consciente de que a prática docente pressupõe a compreensão de ensino-aprendizagem sob o prisma que integra diferentes áreas do conhecimento, assim: “O ensino é uma prática social concreta, dinâmica, multidimensional, interativa, sempre inédita e imprevisível. É um processo complexo que sofre influência de aspectos econômicos, psicológicos, técnicos, culturais, éticos, políticos, afetivos e estéticos.

Nesta perspectiva, privilegiar a produção coletiva dos conhecimentos, implica na necessidade do aprender a aprender, a conhecer, a fazer, conviver e ser por parte do professor, mediador dessa construção. Isso leva à percepção de um movimento de ações pe- 
dagógicas que pressupõem a problematização, e compreensão das diversas faces da realidade, exigindo com isso, uma prática interdisciplinar que consiste, muitas vezes na numa mudança de postura profissional.

Contudo, um trabalho, pautado em atividades integradas não pode ser encarado como algo de momento (modismo), mas o encontro com as adversidades, que exigem uma nova compreensão da concepção de interdisciplinaridade. Nesse sentido Fazenda (2001), afirma que a interdisciplinaridade a partir de alguns elementos como ter atitude interdisciplinar - compreender a vivência do movimento dialético, pensar o novo revendo o velho, de forma que um não se sobressaia em detrimento do outro; e parceria - pensar que todos os envolvidos no processo de transmissão do conhecimento devem dialogar-se, independente da área de conhecimento de cada um, de forma que trabalho seja um todo integrado; totalidade do conhecimento - respeitas as diferenças, as especificidades e pensar as intenções, numa ação conjunta, baseada nos aspecto teórico-metodológicos que embasam o fazer pedagógico.

Para uma ação interdisciplinar, necessita-se então de estratégias metodológicas que sugere mudanças, rupturas não só na forma de educação, sobretudo nas ações, mesmo que isso represente um desafio a ser enfrentado pelos educadores. Significa assim, partir do disciplinar, em que na maioria das vezes os conhecimentos são vistos de forma independente, fragmentas, obedecendo a um currículo, na maioria das vezes também disciplinar e dar espaço a dinâmicas metodológicas que visem à integração dos conteúdos de forma que a construção dos saberes necessários aconteça, mesmo resultando do enfrentamento de situações advindas das mudanças constantes da sociedade do conhecimento. De acordo com Hilton Japiassú, a "Interdisciplinaridade não é algo que se ensine ou que se aprenda, mas algo que se vive" e reconhece que "é fundamentalmente uma atitude de espírito. Atitude feita de curiosidade, de abertura, de sentido de aventura, de intuição das relações existentes entre as coisas e que escapam à observação comum" (JAPIASSU, 1979, p. 15). Assim, o ensino interdisciplinar visa trabalhar com objetos complexos, sair dos limites fixos das previsibilidades disciplinares e lançar-se no universo das instabilidades e incertezas. 
Diante dessas reflexões é que este artigo propõe um diálogo sobre a representação de práticas pedagógicas interdisciplinares no ensino médio, sobretudo no ensino técnico profissionalizante tendo como foco componentes curriculares de diferentes eixos. Sabe-se que o ensino técnico profissionalizante apresenta um currículo compostos por disciplinas do eixo comum, compreendendo a grade básica para o ensino médio e disciplinas do eixo tecnológico, que atendem às especificidades e peculiaridades do curso profissionalizante a que se propõe. É nesse cenário que esse artigo discute uma proposta interdisciplinar desenvolvida no Instituto Federal de Educação, Ciência e Tecnologia Baiano - Campus de Bom Jesus da Lapa, à qual propôs integração entre os componentes curriculares Irrigação e Drenagem - eixo tecnológico e Língua Portuguesa - eixo comum, tendo como principal elo entre esses dois campos, a literatura.

Por meio da Literatura é possível explorar diferentes mundos, de realizar sonhos, de criar possibilidades, ao mesmo tempo em que esconde e revela sentimentos e desejos. O escritor HadjGarm' Oren, desenha a Literatura como reveladora:

[...] todo indivíduo, mesmo o mais restrito à mais banal das vidas, constitui, em si mesmo, um cosmo. Traz em si suas multiplicidades internas, suas personalidades virtuais, uma infinidade de personagens quiméricos, uma poliexistência no real e no imaginário, o sono e a vigília, a www.conedu.com.br obediência e a transgressão, o ostensivo e o secreto, pululâncias larvares em suas cavernas e grutas insondáveis. Cada um contém em si galáxias de sonhos e de fantasias, de ímpetos insatisfeitos de desejos e de amores, abismos de infelicidade, vastidões de fria indiferença, ardores de astro em chamas, ímpetos de ódio, débeis anomalias, relâmpagos de lucidez, tempestades furiosas. (MORIN, 2003. p. 44)

Em um meio em que o sujeito desloca e descentra, em que já não é mais capaz de sustentar sua integridade pois é composto por identidades difusas e fluidas, fruto de processos de diferentes ordens socioculturais. Nesse sentido, a própria concepção do sujeito se caracteriza pelo provisório, variável e problemático, alguém como não tendo uma identidade fixa, essencial ou permanente. É uma fantasia, afirma Hall (2003, p.13), considerar a identidade plenamente unificada, completa, segura, coerente e estável. A chamada crise de identidade pode ser entendida também como um processo mais amplo de deslocamento e 
mesmo de fragmentação do indivíduo moderno. Hall aprofundando ainda mais o conceito de identidade nesse tempo, afirma:

Uma vez que a identidade muda de acordo com a forma como o sujeito é interpelado ou representado, a identificação não é automática, mas pode ser ganhada ou perdida. Ela se tornou politizada. Esse processo é, às vezes, descrito como constituindo uma mudança de uma política de identidade. (de classe) para uma política de diferença. (HALL, 2002, p. 21)

Para Bauman a identidade do sujeito é fruto da contemporaneidade de modernidade líquida ${ }^{1}$ justamente pelas instabilidades, transformações repentinas, relações frágeis, dialogada com indivíduos inconstantes consigo, com os outros e com espaço. Para o sociólogo, urgem nesse emaranhado identidades que flutuam, algumas escolhidas pelos indivíduos e outras lançadas a estes pelos que os cercam. O autor, chama a atenção ainda para o perigo destas identidades:

Há uma ampla probabilidade de desentendimento, e o resultado da negociação permanece eternamente pendente. Quanto mais praticamos e dominamos as difíceis habilidades necessárias para enfrentar essa condição reconhecidamente ambivalente, menos agudas e dolorosas as arestas ásperas parecem, menos grandiosos os desafios e menos irritantes os efeitos. (BAUMAN, 2005, p. 19-20)

Dessa forma, os sujeitos que estão totalmente ou parcialmente "deslocados" em toda parte, são também sujeitos conturbados que não estão em lugar algum. Ainda na perspectiva do autor (2005, p. 17), “identidades", assim como o “pertencimento" "não são estruturas sólidas e garantias para toda a vida, são bastante negociáveis e revogáveis..."

Tem-se ainda a mutabilidade no tempo e no espaço é outro fator a ser considerado na questão da construção identitária, rompendo com a ideia pronta e caminhando para a

\footnotetext{
${ }^{1}$ Expressão afirmada pelo Sociólogo Zygmunt Bauman a "modernidade líquida" refere-se ao momento histórico que vivemos atualmente, em que as instituições, as ideias e as relações estabelecidas entre as pessoas se transformam de maneira muito rápida e imprevisível: "Tudo é temporário, a modernidade $(\ldots)$ - tal como os líquidos caracteriza-se pela incapacidade de manter a forma”. (ZYGMUNT BAUMAN, 2005, p. 18)
} 
discussão e compreensão de sua transformação, seja para rompimento ou reafirmação desta. Em Hall:

A questão da identidade está sendo extensamente discutida na teoria social. Em essência, o argumento é o seguinte: as velhas identidades, que por tanto tempo estabilizaram o mundo social, estão em declínio, fazendo surgir novas identidades e fragmentando o indivíduo moderno, até então visto como um sujeito unificado. A assim chamada "crise de identidade" é vista como parte de um processo mais amplo de mudança, que está deslocando as estruturas e processos centrais das sociedades modernas abalando os quadros de referência que davam aos indivíduos uma ancoragem estável no mundo social. (HALL, 2002, p. 7)

A construção identitária se dá por meio de subjetividades individuais e coletivas e está relacionada a grupos sociais e ao pertencimento territorial.

Nesse debate sobre os processos de construção identitária, no qual todos os sujeitos estão imersos, inclusive professor e aluno, a literatura pode ser considerada um instrumento auxiliador de ajudar na compreensão e interação nos mais diferentes universos.

Com caráter interdisciplinar, a Literatura surge como proposta de superação a fragmentação dos conteúdos. Segundo Lück (2013, p. 24), “[...] se o professor analisar adequadamente o seu cotidiano escolar e vital irá identificar facilmente inúmeras dificuldades que resultam da ótica fragmentadora, o que por si, estabelece a necessidade do enfoque interdisciplinar e globalizador no ensino [...]". Sendo assim, a prática pedagógica interdisciplinar apresenta-se como uma ação que tem como objeto (re)ligar, integrar, unir conhecimentos e saberes.

\section{Irrigação e Drenagem e Língua Portuguesa: um elo possível}

O curso Técnico em Agricultura Integrado ao Ensino Médio, assim como outros cursos de proposta profissionalizante têm um número de componentes curriculares elevado quando integrados ao ensino médio. Pensando em diminuir a sobrecarga do número desses componentes sem interferir no processo de ensino e aprendizagem é que a proposta ora mencionada suscitou. Ao perfazer o Curso Técnico Integrado em Agricultura, os alunos devem cumprir 3400 horas de estudo, em 51 disciplinas, ao longo dos três anos 
do ensino médio, sendo dezenove delas no último ano.

Considerando que o terceiro ano tem, dentre outras demandas, atividades de estágio, estudos preparatórios para o Enem, fica evidente a necessidade buscar alternativas que venham facilitar a aprendizagem diante da extensão dessas atividades a serem cumpridas no decorrer dos semestres letivos. Propor a integração de conteúdos torna-se uma possibilidade viável dentro desse contexto. No entanto, como afirma Ivani Fazenda (2001), a interdisciplinaridade parte de elementos como ter atitude interdisciplinar compreender a vivência do movimento dialético, pensar o novo revendo o velho, de forma que um não se sobressaia em detrimento do outro; e parceria - pensar que todos os envolvidos no processo de transmissão do conhecimento devem dialogar-se, independente da área de conhecimento de cada um, de forma que trabalho seja um todo integrado; totalidade do conhecimento - respeitas as diferenças, as especificidades e pensar as intenções , numa ação conjunta, baseada nos aspecto teórico-metodológicos que embasam o fazer pedagógico.

Diante do exposto e de um planejamento interdisciplinar é que se visualizou a relação entre conteúdos de Língua Portuguesa e Irrigação e Drenagem, às quais tinham em comum palavras-chave como seca, chuvas, água, clima, estações do ano, dentre outras. Eixos distantes até então que comungavam elementos e que a partir do estudo de textos literários trariam conteúdos de diferentes perspectivas uma só discussão, embora em aulas diferentes por meio da leitura de O quinže de Raquel de Queiroz e Vidas secas de Graciliano Ramos.

Inicialmente houve um diálogo entre os docentes envolvidos para identificação de ponto de intersecção entre as disciplinas, alguns já citados acima e observou-se a relação entre planos de ensinos para definição do assunto a ser trabalhado. A escolha da metodologia adotada pelos componentes curriculares, bem como a propositiva de uma ação em que envolvesse a integração não só de conteúdo, mas principalmente de docentes e discentes foi pensada e elabora.

O IF-Baiano Campus Bom Jesus da Lapa é antagonicamente marcado por um lado pela seca que penaliza a região e por outro, pela alta produtividade agrícola concentrada no 
Projeto Formoso ${ }^{2}$, vertentes que justificam a existência de cursos voltados para a área agrícola naquele contexto. Isso posto, a escola direciona parte do ensino a pensar nos alunos que lidam com pequenas propriedades rurais, a maioria delas para a agricultura familiar e que tendem sofrer mais os impactos da falta de chuva na região e em alunos que, direcionam-se ao trabalho nas grandes propriedades à beira do São Francisco para desempenharem a função de técnicos, por exemplo.

Nesse cenário, dos textos O quinze e Vidas secas emergem conteúdos como interpretação textual, análise de manifestação literária, figuras de linguagens, ortografia, características de solo e vegetação do bioma caatinga, recursos hídricos do semiárido brasileiro, uso da água de forma eficiente para realizar a irrigação e promover a produção de alimentos, assuntos convergentes às duas disciplinas.

Os alunos foram incumbidos de realizar a leitura das obras em um período de 20 dias e paralelamente, como método de ensino, os componentes curriculares utilizaram de aula expositiva e dialogada, estudo de fragmentos de texto das obras supracitadas, promovendo assim a convergência para o cumprimento dos assuntos escolhidos. Tanto nos componentes curriculares Língua Portuguesa e na Irrigação e Drenagem, as aulas tiveram como elemento principal para a discussão, parte do texto das obras literárias. A turma foi dividida em grupos de quatro alunos para facilitar o debate e compreensão dos assuntos. O texto proposto, além de ser analisado na íntegra, serviu como referência para o aprofundamento de assuntos específicos dos dois componentes curriculares.

\section{Irrigação e Drenagem e Língua Portuguesa: exercitando a interdisciplinaridade por meio da Literatura}

Ao pensarmos a prática pedagógica que visa estabelecer um diálogo entre disciplinas distintas, e, em nosso caso de eixos diferentes (comum e tecnológico), é necessário refletirmos inicialmente sobre como se dá uma prática efetivamente interdisciplinar.

\footnotetext{
${ }^{2}$ Perímetro de Irrigação Formoso no município de Bom Jesus da Lapa que tem como foco a moderna produção agrícola.
} 
O conceito de interdisciplinaridade não é algo que esteja claramente definido nos estudos científicos brasileiros, pois, ainda perduram inúmeras discussões sobre seus aspectos. Entretanto, Zabala (2002, p. 33) descreve a interdisciplinaridade como sendo "a interação entre duas ou mais disciplinas, que podem implicar transferência de leis de uma disciplina a outra, originando, em alguns casos, um novo corpo disciplinar, como, por exemplo, a bioquímica ou a psicolinguística”. Assim, considerando seu caráter polissêmico, podemos tomá-la como um diálogo que leva disciplinas distintas a cooperarem entre si.

Neste sentido, ao pensarmos o trabalho docente interdisciplinar, prevista na organização didática do IF Baiano, podemos separar as ações em três níveis, conforme aponta Lenoir (1998) Para a teórica, a interdisciplinaridade pode ser compreendida nos níveis: curricular, didático e pedagógico.

O nível curricular pressupõe o estabelecimento de uma ligação complementar entre as diferentes matérias escolares, a fim de permitir o surgimento do currículo escolar. No plano didático, a interdisciplinaridade objetiva articular o currículo e sua inserção nas situações de aprendizagem. E o terceiro nível, o pedagógico, no qual atuamos nesta experiência, que é o espaço da ação em sala de aula. Neste, prática leva em consideração a dinâmica real da aula e todos os fatores internos e externos envolvidos no processo de ensino e aprendizado.

Considerando os aspectos supracitados, entendemos, então, que a interdisciplinaridade é um processo que trabalha um conhecimento vivo, que está em constante transformação, que faz sentido para professores e alunos e promova o diálogo entre pessoas e disciplinas curriculares. Sendo assim, nosso desafio prático foi pensar como fazer dialogar duas disciplinas de eixos distintos, no intuito de promover uma ruptura com a fragmentação, divisão entre eixo tecnológico e eixo comum, existente nos cursos técnicos integrados ao ensino médio da instituição.

Ao pensarmos o diálogo entre Língua Portuguesa/literatura e Irrigação e Drenagem, consideramos as inúmeras dificuldades de leitura e interpretação que os alunos trazem do ensino fundamental. Por isso, a proposta de trabalho apresentada, buscou promover a leitura de forma significativa, considerando a vivência social e cultural dos 
estudantes.

A escolha das obras estudadas também considera o curso escolhido pelos alunos e a realidade semiárido baiano, onde vivem os estudantes. Neste sentido, a leitura literária deve proporcionar a experiência de ação cultural, social e política, em que o leitor tem o papel fundamental na ressignificação do texto lido, isto é, uma forma de ler o mundo que os cercam. Dessa maneira, a discussão levantada com a turma partiu de algumas questões elaboradas previamente, considerando o cenário geográfico e histórico/cultural apresentados nas obras.

Inicialmente discutimos as características do solo da região em que residem, observando aspectos como a quantidade de chuva a cada ano, quais são as características da vegetação da caatinga e como as famílias armazenam água. Para tanto, após a leitura na íntegra das obras, alguns trechos foram selecionados para nortear a discussão como em:

Novamente a cavalo no pedrês, Vicente marchava através da estrada vermelha e pedregosa, orlada pela galharia negra da caatinga morta. Os cascos do animal pareciam tirar fogo nos seixos do caminho. Lagartixas davam carreirinhas intermitentes por cima das folhas secas do chão que estalavam como papel queimado. O céu, transparente que doía, vibrava, tremendo feito uma gaze repuxada. Vicente sentia por toda parte uma impressão ressequida de calor e aspereza. Verde, na monotonia cinzenta da paisagem, só algum juazeiro ainda escapou à devastação da rama; mas em geral as pobres árvores apareciam lamentáveis, mostrando os cotos dos galhos como membros amputados e a casca toda raspada em grandes zonas brancas. E o chão, que em outro tempo a sombra cobria, era uma confusão desolada de galhos secos, cuja agressividade ainda mais se acentuava pelos espinhos. (QUEIROZ, 2993, p. 13-17)

Como é possível observar, o excerto acima apresenta algumas características da paisagem de uma região no campo ficcional que pode ser relacionada com a realidade local dos alunos. A menção à cor avermelhada da estrada e sua pedregosidade, remete a estudos de morfologia que são características presentes e observáveis nos solos que permitem distinguir um determinado tipo de solo dos demais. Assim, foi possível que os estudantes pudessem debater sobre as principais características dos solos do semiárido. Outro aspecto analisado a partir da figura de linguagem "O céu transparente que doía”, são os elementos 
do clima, muito marcantes na região Nordeste, como radiação solar abundante, temperatura do ar e umidade relativa. A resultante climática desta região é um balanço hídrico negativo, ou seca, devido à baixa precipitação pluviométrica e elevada perda de água por evaporação, que de forma metafórica a autora relata que o "céu tremia feito uma gaze repuxada". Também foi possível discutir as características do bioma caatinga como a formato da vegetação e sua coloração.

Esta experiência relacional entre leitura literária e tema técnico, demonstra, neste ponto, a importância de se pensar na leitura significativa no contexto escolar. Como mencionado, muitos estudantes chegam do ensino fundamental com nítidas dificuldades de leitura e interpretação, fator promovido pela deficiência em apresentar aos mesmos um contexto de leitura que ultrapasse a mera decodificação e elaboração de fichas literárias. Ao levar o aluno a pensar a realidade social e geográfica onde está inserido, observar o contexto histórico, estético e literário das obras em discussão, o texto transcende a esfera do código por si só e passa a produzir um sentido real e prático para o estudante.

Ao se tratar do ensino técnico em agricultura, a turma traz em si um perfil de alunos já com uma certa afinidade com dinâmicas relativas ao ambiente, à agua, à lida com terra, uns menos outros mais devido à própria disparidade existente entre o nível de conhecimento dos alunos, proveniente de diversas questões. Nesse aspecto, tornar o texto literário um mediador de discussões em diferentes áreas do conhecimento é uma possibilidade real. Assim como Vidas secas, outros textos literários podem ser explorados interdisciplinarmente por diferentes eixos, como é o caso de O quinz̧e, de Rachel de Queiróz, ao trazer a problemática da escassez de chuva na região Nordeste e as implicações que esta causa na vida dos nordestinos. Esse romance, ao tratar da seca como fio condutor da narrativa, leva o leitor a refletir sobre a própria condição humana, por meio de uma reflexão em que a seca impõe provações desumanas aos indivíduos, e a mesma exalta seus atributos como resistência, persistência, subsistência, crença, caridade, que servem como a garantia para ser gente.

Com uma linguagem simples, característica do sertanejo humilde, é possível que tanto componente Língua Portuguesa quanto o componente Irrigação e Drenagem 
trabalhem fatores relacionados à linguagem. Salienta-se, no entanto, que mesmo se tratando de uma proposta pedagógica interdisciplinar, carece buscar nos textos literários, recortes que facilitem a dinâmica nas diferentes áreas. $O$ fragmento a seguir exemplifica $o$ desenvolvimento de um diálogo entre os dois componentes:

Vicente lastimou-se:

- Inda por cima do verãozão, diabo de tanto carrapato... Dá vontade é de deixar morrer logo!

- Por falar em deixar morrer... o compadre já soube que a Dona Maroca das Aroeiras deu ordens pra, se não chover até o dia de São José, abrir as porteiras do curral? E o pessoal dela que ganhe o mundo... Não tem mais serviço pra ninguém.

Escandalizado, indignado, Vicente saltou de junto da jurema onde se encostava:

- Pois eu, não! Enquanto houver juazeiro e mandacaru em pé e água no açude, trato do que é meu! Aquela velha é doida! Mal empregado tanto gado bom!

E depois de uma pausa, fitando um farrapo de nuvem que se esbatia no céu longínquo:

— E se a rama faltar, então, se pensa noutra coisa. Também não vou abandonar meus cabras numa desgraça dessas... Quem comeu a carne tem de roer os ossos...

$\mathrm{O}$ vaqueiro bateu o cachimbo num tronco e pigarreou um assentimento. Vicente continuou:

- Do que tenho pena é do vaqueiro dela... Pobre do Chico Bento, ter de ganhar o mundo num tempo destes, com tanta família!...

— Ele já está fazendo a trouxa. Diz que vai pro Ceará e de lá embora pro Norte...

Vicente se dirigiu ao seu velho pedrês, enquanto o vaqueiro comentava:

- Nem parece que este bicho come milho todo dia... já tão descarnado!...

Vicente montou

— Vocês fiquem por aqui, até acabar. Eu tenho que fazer lá em casa. (QUEIROZ, 1993, p. 15)

Reportando esse fragmento para Irrigação e Drenagem, é possível dialogar com a narrativa literária de $O$ quinze com debates sobre as características do verão no nordeste, quantidade de chuva (milímetros) por ano na região, de como as pessoas armazenam água, como calcular o armazenamento de água no solo, relações hídricas de espécies de plantas xerófitas, conteúdos referentes à ementa da disciplina do curso Técnico em Agricultura Integrado. Para além, a análise do bioma caatinga, o conceito de seixos, o grau de 
intemperismo do solo dessa caatinga, são discussões que permeiam as aulas sem deixar de lado o enfoque literário do texto. Observa-se também o cuidado da autora citar plantas a exemplo de jurema, juazeiro e mandacaru, sinônimo de resistência à seca, revelando a diversidade genética do bioma e a tolerância que algumas plantas apresentam. A perda de folhas de algumas espécies de plantas é uma reação preventiva para reduzir a transpiração e conservar água nos seus tecidos, de modo que consiga sobreviver a eventos de estiagem. A prática interdisciplinar mencionada nesse artigo permitiu com que alunos percebessem, por meio de finalidades distintas (eixo técnico e eixo comum) que as plantas que representam o cenário do livro e escapou da seca são as mesmas vistas na prática de sala de aula e que os mecanismos que as plantas utilizam para conservar água, tratados pela narrativa literária com o olhar poético, são os mesmos dos processos de irrigação e drenagem.

Por outro lado, tem-se a linguagem explorada e o vocabulário, os quais ultrapassam as fronteiras e limites dos componentes curriculares, uma vez que a interdisciplinaridade vai além do disciplinar. Em Vidas secas, por meio da linguagem, a narrativa exterioriza informações, experiências etc., sendo indivíduos interpessoais, subjetivos. Graciliano transforma as palavras em representações concretas, embebendo-se de uma realidade carregada de significado. Com uma narrativa que retrata o sertão nordestino e, ao mesmo tempo o semiárido do Oeste Baiano, ainda que sob uma representatividade simbólica, Vidas Secas protagoniza a história de uma família pobre que, obrigados pela circunstância da seca, fogem, sem destino, da miséria e da fome e vão á busca de sobrevivência, uma vez que "a fome apertara demais os retirantes e por ali não existia sinal de comida" (RAMOS, 2003, p. 09).

Vidas Secas desperta para a reflexão dos problemas existentes no universo rural, uma vez que o autor apresenta o espaço rural em uma dimensão muito ampla, descobrindoo, reinventando-o, mas também reinterpretando-o, discussão que perpassa pela dimensão tanto da Irrigação e Drenagem quanto da de Língua Portuguesa. 
Ao mesmo tempo em que exterioriza a sua preocupação com os problemas existentes no meio rural, permite questionamentos desses problemas sob a ótica técnica assim como indagar qual a vegetação, qual a condição hídrica do cenário nordestino, qual a relação desses aspectos com a falta e com a presença da chuva, como mostra a fragmento abaixo:

Agora a lagoa estava cheia, tinha coberto os currais que ele construíra. O barreiro também se enchera, atingia a parede da cozinha, as águas dele juntavam-se às da lagoa. Para ir ao quintal onde havia craveiros e panelas de losna, Sinhá Vitória saía pela porta da frente, descia o copiar e atravessava a porteira de baraúna. Atrás da casa, as cercas, o pé de turco e as catingueiras estavam dentro da água. As goteiras pingavam, os chocalhos das vacas tiniam, os sapos cantavam. O som dos chocalhos era familiar, mas a cantiga dos sapos e o rumor das goteiras causavam estranheza. (RAMOS, 2003, p. 37)

O texto literário propõe, questionamentos que ultrapassam também a ordem técnica, assim tanto na aula de Língua Portuguesa quanto de Irrigação e Drenagem, novas perguntas foram surgindo ao longo dos debates, como por exemplo: o que foi violado segundo o autor, com a chegada da chuva?; por que o autor considera os sapos invisíveis habitantes invisíveis da terra?; e a relação dessas alterações com os sistemas de drenagem. O excerto que segue reporta para essa abordagem:

Tudo estava mudado. Chovia o dia inteiro, a noite inteira. As moitas e capões de mato onde viviam seres misteriosos tinham sido violados. Havia lá sapos. E a cantiga deles subia e descia, uma toada lamentosa enchia os arredores. Tentou contar as vozes, atrapalhouse. Eram muitas, com certeza havia uma infinidade de sapos nas moitas e nos capões. Que estariam fazendo? Por que gritavam a cantoria gorgolejada e triste? Nunca vira um deles, confundia-os com os habitantes invisíveis da terra e dos bancos de macambira (planta - bromélia). Enrolou-se acomodou-se, adormeceu, uma banda aquecida pelo fogo, a outra banda protegida pelas nádegas de Sinhá Vitória. (RAMOS, 2003, p. 37)

Nota-se dessa forma, que a literatura em sala de aula aproxima a realidade do aluno, proporciona a integração entre componentes e conteúdos distintos ao mesmo tempo em que investe no hábito pela leitura. Por isso, é importante que sejam pensadas práticas interdisciplinares que haja integração entre professores, alunos, conteúdos e leituras e 
conhecimentos prévios, conforme sugere Cosson: "[...] é papel de o professor partir daquilo que o aluno já conhece para aquilo que ele desconhece, a fim de se proporcionar o crescimento do leitor por meio da ampliação de seus horizontes de leitura" (2014, p. 35).

\section{Considerações finais}

A atuação em uma prática interdisciplinar em que se coloca lado a lado literatura/leitura e uma disciplina técnica como irrigação e drenagem requer algumas reflexões sobre o papel profissional do professor.

É certo que o mundo contemporâneo traz novos desafios e possibilidades que levam à necessidade de se pensar continuamente sobre o papel da escola e, consequentemente, sobre o papel do professor no processo de construção do conhecimento escolar. Neste sentido, propõe Veiga (2008), que há uma ampliação no papel docente, tendo em vista o fato de que compete ao professor muito mais que apenas ministrar aulas.

A atividade docente é ampliada porque outros desafios são inseridos continuamente ao processo de ensinar, como a diversidade e a pluralidade sociocultural e as necessidades do mundo do trabalho que trazem os alunos que se inserem em um curso técnico integrado ao ensino médio. Em face disso, torna-se necessário redimensionar as formas de ensino, no sentido de que a escola e o professor possam trabalhar com as necessidades apresentadas no contexto social, político, econômico e cultural em que estão inseridos.

Entendemos que a interdisciplinaridade traz ao âmbito educacional uma nova perspectiva pedagógica e metodológica que favorece, conforme propõe Fazenda (2002) novas formas de leitura e aproximação das realidades sociais, constituindo novas leituras das dimensões socioculturais humanas. Isto é, a prática interdisciplinar exige que o professor busque novas perspectivas de atuação, visando um movimento de construção do aprendizado que perpasse outras áreas do conhecimento.

A leitura na escola, muitas vezes, se restringe ao aspecto reducionista respondendo apenas as questões propostas pelo professor ou o autor do livro, a partir de elaboração de fichas de leitura ou fichas literárias. Já a proposta interdisciplinar visa considerar a leitura 
não apenas em seu caráter unidirecional mas em diálogo com a realidade e com o outro. Ao se escolher um trabalho conjunto abordando a prática da leitura literária, consideramse os múltiplos significados e relações interculturais e sociais possíveis nos textos selecionados. Assim, a prática de leitura pode atender as defasagens de leitura e interpretação trazidas pelos alunos, bem como deixa de contemplar apenas seu caráter disciplinar, para considerar outros saberes pessoais e técnicos. Para tal, é de fundamental importância o tempo de planejamento que trace claramente os objetivos e conteúdos a serem trabalhados.

A partir da proposta executada nas disciplinas de Língua Portuguesa e Irrigação e Drenagem, foi possível notar um maior interesse dos alunos e assimilação dos conteúdos/temas discutidos. Assim, verifica-se a necessidade de manter uma constante busca pela ruptura do conhecimento linear, isolado, a fim de construir práticas que valorizem a contextualização do conhecimento, bem como a transdiciplinaridade ${ }^{3}$. Não basta promover o acúmulo de conteúdos, mas estabelecer relações significativas entre estes e as disciplinas e, principalmente, entre as situações sociais e culturais em que se inserem os estudantes.

\section{LENGUA PORTUGUESA Y RIEGO Y DRENAJE: LA INTERDISCIPLINARIEDAD LITERARIA COMO ELO}

RESUMEN: Este trabajo presenta una reflexión sobre la práctica interdisciplinaria en el ámbito del Instituto Federal de Educação, Ciencia y Tecnologia Baiano (IF-Baiano), campus de Bom Jesus da Lapa, entre las asignaturas Riego y Drenaje y Lengua Portuguesa. La práctica se realizó con clases desde el tercer año del Curso Técnico Integrado de Agricultura, utilizando como punto de partida la lectura literaria de las obras O quinze de Raquel de Queiroz y Vidas secas de Graciliano Ramos. Por lo tanto, se discutieron algunos temas que convergen a las dos disciplinas, tales como: interpretación textual, figuras de lenguaje, ortografía, características del suelo y la vegetación del bioma caatinga, recursos hídricos de la región semiárida brasileña, uso eficiente del agua para llevar a cabo el riego y promover producción de alimentos Se pudo observar que es posible el diálogo entre las asignaturas del eje tecnológico y el eje común, lo que trajo una mayor participación e interés de los estudiantes, ya que los contenidos se discutieron en función de la realidad local, considerando el perfil de los que ingresan al curso.

\footnotetext{
${ }^{3}$ De acordo com o que orienta a Lei de Diretrizes e Bases da Educação Nacional - LDB (Lei 9394/96), a transdisciplinaridade é a busca de saberes externos e transversais às disciplinas, dentro da produção do conhecimento e dos processos educativos.
} 
PALABRAS-CLAVE: Interdisciplinariedad; Lectura Literaria; Lengua Portuguesa; Riego y Drenaje.

\section{REFERÊNCIAS}

BAUMAN, Zygmunt. Identidade. Tradução de Carlos Alberto Medeiros. Rio de Janeiro: Jorge Zahar Editor, 2005.

BRASIL. Lei de Diretrizese e Bases da Educaşão Nacional. Lei número 9394, 20 de dezembro de 1996.

COSSON, Rildo. Círculos de leitura e letramento literário. São Paulo: Contexto, 2014.

FAZENDA, Ivani Catarina Arantes. Dicionário em construção: interdisciplinaridade. 3. ed., São Paulo: Cortez, 2002.

FAZENDA, Ivani Catarina Arantes. Integração e interdisciplinaridade no ensino brasileiro: Efetividade ou ideologia. São Paulo: Edições Loyola, 2011. . (Org.). Dicionário em construção: interdisciplinaridade. São Paulo: Cortez, 2001.

HALL, S. A identidade cultural na pós-modernidade. 7. ed., Rio de Janeiro: DP\&A, 2002 JAPIASSU, Hilton. Prefácio. In: FAZENDA, Ivani Catarina Arantes (Org.). Integração e interdisciplinaridade no ensino brasileiro: efetividade ou ideologia? São Paulo: Loyola, 1979.

LUCK, H. A Gestão Participativa na escola. Petrópolis: Vozes, 2013.

LENOIR, Y. Didática e interdisciplinaridade: uma complementaridade necessária e incontornável. In: FAZENDA, I. C. A. (Org.). Didática e interdisciplinaridade. Campinas: Papirus, 1998.

MORIN, E. Os sete saberes necessários à educaşão do futuro. 2. ${ }^{a}$ ed., São Paulo: Cortez, 2003.

QUEIROZ, Rachel de. O quinze. São Paulo: Siciliano, 1993. p. 13-17.

RAMOS, G. Vidas secas. 89. ed.,, Rio de Janeiro: Record, 2003.

SANTOMÉ, J. T. Globalização e interdisciplinaridade: o currículo integrado. Porto Alegre: Artes Médicas, 1998.

VEIGA, Ilma Passos Alencastro. Docência como atividade profissional. In: VEIGA, I. P. A.; D"AVILA, C. M. Profissão docente: novos sentidos, novas perspectivas. Campinas: Papirus, 2008. - A prática pedagógica do professor de didática. 3. ed., Campinas: Papirus, 1996.

ZABALA, Antoni. Enfoque globalizador e pensamento complexo. Porto Alegre: Artmed, 2002. Recebido em: 30/04/2020. Aprovado em: 30/06/2020. 